\title{
Emerging issues and current trends in assistive technology use 2007-2010: practising, assisting and enabling learning for all
}

\author{
Chris Abbott ${ }^{1}$, David Brown ${ }^{2}$, Lindsay Evett ${ }^{2}$, and Penny Standen ${ }^{3}$ \\ ${ }^{1}$ Department of Education \& Professional Studies, King's College London, London, UK, ${ }^{2}$ School of \\ Science \& Technology, Nottingham Trent University, Nottingham, UK, and ${ }^{3}$ Faculty of Medicine \& \\ Health Sciences, University of Nottingham, Nottingham, UK
}

\begin{abstract}
Following an earlier review in 2007, a further review of the academic literature relating to the uses of assistive technology (AT) by children and young people was completed, covering the period 20072011. As in the earlier review, a tripartite taxonomy: technology uses to train or practise, technology uses to assist learning and technology uses to enable learning, was used in order to structure the findings. The key markers for research in this field and during these three years were user involvement, AT on mobile mainstream devices, the visibility of AT, technology for interaction and collaboration, new and developing interfaces and inclusive design principles. The paper concludes by locating these developments within the broader framework of the Digital Divide.
\end{abstract}

\section{Introduction}

This literature review is designed to build on a previous publication (Abbott 2007a) and to indicate changes in the scope and trends found in assistive learning technologies and related research. The literature review is one of the outcomes of the UK Economic and Social Research Council (ESRC)-sponsored seminar series:

'Researching the use of assistive technologies by children and young people: Interdisciplinary Perspectives' These seminars were attended by established and early career researchers involved with aspects of assistive technologies from UK and European universities. Assistive learning technologies, in this context, cover a range of digital technologies which assist or enable learning. Some of these are hardware-based (such as keyguards, mouse alternatives or voice output devices), others are software-based (such as onscreen keyboards, writing frames and predictive word processing) but all have the potential to be emancipatory or of little effect, depending upon how they are used. This literature review, however, is arranged not by type of device but 
through an established taxonomy of use. Our focus throughout is on the use of assistive learning technologies, but for the sake of brevity we use the term assistive technologies in the remainder of the paper.

\section{Methodology}

The method for the development of this literature review was as follows. The authors attended each of the seminar series, the aim of which was to identify key trends and developments within the field of assistive technologies. The four seminars each consisted of presentations, panels and discussion fora on one of four key topics: Theoretical frameworks for researching the use of assistive technologies; Involving young people with disabilities in assistive technologies research; Cross-disciplinary academic and professional perspectives; and Researching assistive technologies for communication and literacy. Following their attendance at all four seminars, the authors then defined the criteria for inclusion in this review and the process by which literature would be searched. The new version of ISO 9999 (ISO 9999:2011) was found to be flexible enough to be able to include many examples of new types of ICT AT. The ISO itself is being reviewed and includes the definition "assistive products used by persons with a disability, but which require the assistance of another person for their operation" but is not restricted to those products. Given the wide ranging use of technology presented in the series which did not always neatly fit within this definition, and review of the inclusion criteria of the European Thematic Network of Assistive Technologies (ETNA: Framework 7 Co-operation project) a more forwardlooking inclusion criteria was adopted.

The authors then adopted a taxonomy to classify ATs (assistive technologies), building on a previous review where ATs were classified by use rather than form (Abbott 2007b):

- Technology uses to train or practise

- Technology uses to assist learning

- Technology uses to enable learning

Although there is some sense in which the adopted classification can be seen as denoting chronological stages in the development of assistive technology, we would suggest that the taxonomy is a classification by use rather than by stage of development, and it is not intended to indicate themes derived from the review. The authors then held post-seminar meetings to classify the literature identified using this taxonomy: the group involved was a multi-disciplinary team with expertise in Education, Special Educational Needs, Experimental Psychology and 
Computer Science. The period covered was 2007 to 2011, and involved a search of 27 academic journals, conference proceedings and the ESRC seminar series.

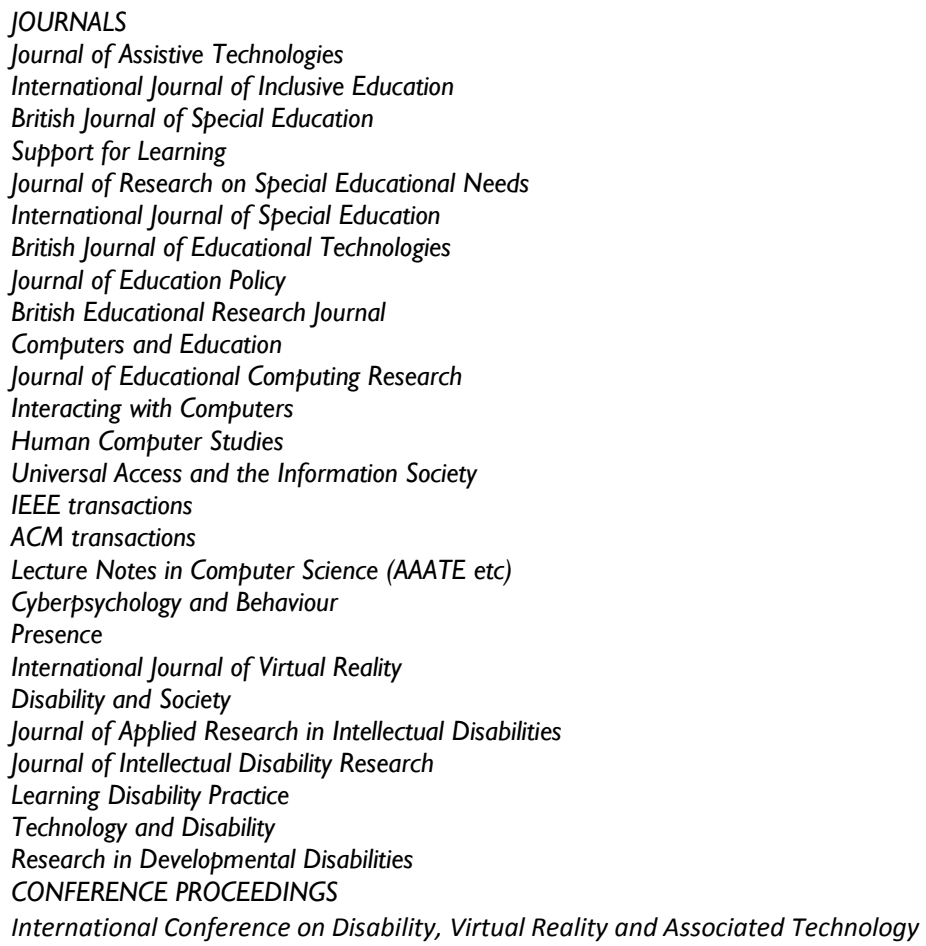

Keywords used:

Assistive Technology

Assistive Technologies

ICT and Special Educational Needs

ICT and SEN

Learning Difference

Learning Difficulties

Learning Disabilities

e-Inclusion

Technology and Disability

In addition to extending the scope of the previous 2007 literature review published by Futurelab (Abbott 2007a), the review took account of a recent review of European research which found very limited amounts of research, very little that was longitudinal in nature, and the link between this and funding, since "the number and focus of studies seems to relate to research funding that has been available in Europe" (Salminen 2008: 176). The current paper attempts to provide a descriptive analysis of much of the extant literature in Europe. We acknowledge the Eurocentric nature of much of our review, with our intention being to bring to wider 
recognition the nature of scale of this research and scholarly activity. We also acknowledge the longer history of publication within this area in the United States and we cite relevant North American research where this supports or even contradicts European findings. We also cite some of the early research appearing from Asian countries, again in order to acknowledge relevance to the European studies which form our major focus.

Salminen also makes the point that longitudinal research is needed in the sector, and that its complexity may also be part of the reason for the apparent dearth of European literature.

AT is a complex phenomenon that takes place in real life, involving technology, humans and activity, while taking place in different contexts... Given the complexity of the whole phenomenon, it is a significant challenge to decide on the correct [methodology]... It may even be that methodological compromises in the studies related to children and AT do not fulfil the criteria of those who fund research or review journal articles, and thus the whole research area becomes more marginalised than it deserves.

(Salminen 2008: 177)

Issues of classification, nomenclature and definition have been addressed by others attempting to provide an overview of assistive technologies, often when editing special issues of journals. Editors such as Raymaekers (2009) have sought to bring clarity and understanding to new areas: in this case, enactive interfaces. Gesture input and haptic devices are among the technologies in the same special issue of Interacting with Computers, edited by Raymaekers (2009), and these are technologies to which we will return.

Quite rightly, it is unacceptable today to defend research methodologies that do not involve users of technologies themselves. In the past, young users and those who support them have not often been asked for their opinions or been involved in research. This has begun to change, however, particularly within projects such as Devices for Dignity (www.devicesfordignity.org.uk). At an early stage of that project, researchers asked assistive technology users what they wanted from the technologies they use, and the questionnaire they developed for this is now available to others (Townend \& Judge 2009). In another more transitory initiative, more than 600 teachers in Australia were involved in a rapid data gathering exercise at an Australian conference (Abbott 2010) and the response alone indicated the enthusiastic willingness to take part if only users of assistive technology are given the opportunity to do so. Calls within the literature for the adoption of concepts such as 
Universal Learning (Rose \& Strangman 2007) and Design for All (Horton 2006: xvi) recognise the wider conceptual framework of individual learner difference. A model of learner difference, acknowledging variety rather than isolating and labelling particular learners also resonates with the findings of an earlier study (Forrester Research 2004) which showed that many computer users have a disability and also that, paradoxically, many users of assistive technology do not have a disability.

In order to present our analysis, we do so under three headings. These headings are derived from the taxonomy that informed the previous literature review written by one of us (2007b), and which has since been adopted by others (Galloway 2009). We have adopted these same headings in order to identify changes since our previous literature review. Although we present our findings under three broad headings, we recognise that not all research which is relevant to the topic can be placed neatly into these categories. We can learn from UserCentred Design (UCD) approaches for example, which encourage consideration of all users, including carers and trainers. The significant role of carers in the successful use of assistive technology is also made clear elsewhere (Williams 2008; Bailey 2009; Bailey \& Bunning 2010). There is a growing and welcome literature around technology use policy (de Jonge 2007) and disability rights (Konur 2010) which cannot easily be fitted into a neat tripartite approach. Too often, school Virtual Learning Environments (VLEs) do not meet the World Wide Web Corporation's Web Content Accessibility Guidelines (currently version 2.0; W3C, 2008a; 2008b; 2008c) or follow good practice guidelines such as W3C and Horton (www.universalusability.com/access_by_design/index.html), as well as general advice from agencies such as Techdis (www.jisctechdis.ac.uk), Fix the Web (2011) and others (Evett \& Brown, 2005; Brown et al 2010).

\section{Technology uses to train or practise}

It has been suggested (Abbott 2007a) that technology fitting into this category, often of a drill and practice nature, has too often been seen as central to the needs of those with learning differences, despite the close association with simplistic behaviourist models of learning. This use of technology is persistent however, and continues to be practised and researched. Too often, unfortunately, the focus of this research is an evaluation of a particular product, often by someone closely associated with that product or its originators. Such research, although not without interest, is likely to be unconvincing within wider research circles. 
Some technologies have been developed to train for specific skills or practices. A game prototype (Umanski et al 2010), designed for use by speech and language therapists, presents sequences of syllables in specific rhythmic patterns, with this interim paper describing limitations to date and further developments proposed. In Taiwan, a group of researchers developed a music-learning system aimed at those who have a hearing impairment (Yang et al 2007). The aims of the system were to train in the differentiation of tone, and to enable the learning of what is described as song. In its present state, however, the system appears to offer essentially practice opportunities for identifying single notes. Liu and Hong (2007) attempted a more holistic type of support for students with a hearing-impairment through the development of extra-curricular support via smart phone, which was found to be manageable and effective. The focus for Lin et al (2008) was software to teach word recognition to those identified as having learning difficulties, although it would seem likely that the program outlined would provide practice rather than learning opportunities. Navigation strategies were the focus for a group of researchers (Groenewegen et al 2008) who developed virtual worlds which could be used to train learners for independent living.

The rapid development of access to the Internet for all users has led to a similarly rapid development of Webbased training sites and other mechanisms for providing online practice. Researchers from five European countries working on the SEVERI project (Starcic \& Niskala 2010) created an e-learning environment for students with a range of special educational needs, finding evidence of greater student autonomy as a result, and an increased ability to manage communication difficulties.

Animated sequences have long been popular as a medium for training. Researchers in Germany (Spannage et al 2008) compared the effectiveness of animated sequences and other devices such as training wheels (programs with reduced functionality) or text manuals. The task involved was to learn how to use a spreadsheet to solve Maths or Physics problems. Mathematics was also the curriculum area that was the focus for the work by Brown and Standen (2011), who present some emerging evidence for the affordances of gaming technology for mathematical understanding. A similar curricular focus is found in Seo and Bryant (2009), a meta-study of 11 accounts of the effect of computer-assisted instruction (CAI) on the mathematical understanding of students with learning disabilities. In the latter case, however, the team found that CAI was not found to be significantly effective in these studies, although it was recognised that the group size caused methodological difficulties. Building on this work, Seo and Woo (2010) again focus on Mathematics and students with learning disabilities 
in their study of the use of a particular CAI program. As with all such single-product evaluation papers such as this one, there are limitations to what can be claimed, especially where the research team are also the originators of the product.

Therapists, as well as teachers, have long used technologies within educational environments, or to support what goes on there. Saz et al (2009) describe a study involving Speech and Language Therapists (SLTs) working with a range of young people with a degree of language impairment. Recognising an increasing demand for SLT support, the team developed a semi-automated system to provide interactive speech therapy. A more recent development linked to this type of technology implementation, though often transcending its limitations, is the use of what have come to be known as serious games, for example being used to teach employment skills to young people with intellectual disability (Sik Lányi et al, 2010). Such games have been described (Puttnam, 2009) as ethical laboratories that show you how things are and how they could be, and can therefore be used to influence change. Multiple player online games and other social networking tools offer not just a mechanism for online presence; they also serve as incubators of a new pop cosmopolitanism and an ability to navigate in an increasingly globalised, diverse and socio-technical world (Steinkuler, 2008).

Savidis et al (2007) describe how they have used serious games with people with learning disabilities in Crete, finding these to be pleasant, motivating and highly engaging interactive experiences, improving training and learning. Motivation and engagement were also issues that arose during an intervention by a team of psychologists in the Netherlands who aimed to explore the potential of technology to significantly improve short term memory (van der Molen et al 2010) and they claim that this is "the first demonstration that working memory can be effectively trained in adolescents with mild to borderline intellectual disabilities" (van der Molen et al 2010: 433). An earlier study (Brown et al 2008) showed the effectiveness of games to improve the memory skills of people with intellectual disability.

In order to access any of these technologies, appropriate interfaces need to be available. These continue to be researched and developed, with Visell (2009) providing a review of, for example, varieties of touch interface and the principles of tactile sensory substitution, and Evett et al (2009) considering the use of Wii technology. Touch was the focus of research in Sweden (Moll et al 2010) on the extent to which an audio and haptic interface encouraged collaboration between users with and without vision. Another interface used by a team in 
the United States was a PDA (personal digital assistant) as a cueing device. As part of a programme to teach fire safety, the researchers (Burke et al 2010) worked with a six young adults on the Autism Spectrum and found that it was only after the introduction of the cueing system that five of the participants could respond to the behavioural skills training, assisting the prospects of learners with ASD being employed in future.

\section{Technology uses to assist learning}

We suggest that "technology that assists is usually linked to the need to compensate for a physical disability or difficulty" (Abbott 2007a: 13). It is for this reason, above all others, that we find ourselves in this section to be more often reverting to the use of categories of impairment as a mechanism by which to consider the range of practices discovered. Although there is some discussion in the literature of basic design principles for inclusion (Langdon \& Thimbleby 2010), much of the research into technology uses to assist learning is focussed on a particular technology or way of working. There has also been a particular emphasis on the needs of those with sensory impairment, although more recently there has been more attention to the needs of users with cognitive difficulties, as in Gregor and Dickinson (2007), who propose an interaction design perspective when creating resources for this group of users. In particular, they discuss the cognitive load associated with particular technology-related activities and with the needs of those with dyslexia in mind. Davies and Dautenhahn (2010) have published guidelines for the design of software - and software trials - for children with autism. McMorran (2009) provides a detailed case study of a young head switch user who eventually progressed to the use of eye gaze. The EU-funded COGAIN project also examined eye-gaze technology, and the report (Majaranta \& Bates 2009) of a conference set up by the project provides a useful summary of the work completed and an introduction to the more specific papers included in this special issue.

Although assistive technologies have been in use for many years, little is known about how they are used. This was the focus for McGuiness and Farrand (2010) who investigated how people use their voice output communication aids (VOCAs). They found that VOCAs enabled greater communicative range and autonomy for some users, but not all. An international team investigated a similar area (Lancioni et al 2007) in their study of three adolescent VOCA users with more severe learning difficulties. A team from the Child Computer Interaction Group at the University of Central Lancashire looked at the use of pen, keyboard and graphics tablet for the entry of text (Read 2007). They found that lengthier texts were produced by the children (who were aged 7 and 8 years) using a graphics tablet than the other alternatives. Occupational therapy research has much to 
offer in this area, particularly with the clear identification of the type and nature of difficulty with handwriting (Hen, Josman \& Rosenblum 2008), and the potential for computer-based rehabilitation.

Speech recognition is now a well-established technology which is much more affordable than was previously the case. A team at the University of Southampton looked at the potential of Automatic Speech Recognition (ASR) for users of assistive technology (Wald \& Bain 2008), and found that, at least within the learning context examined, there was clear potential for ASR use to assist with note-taking, online searching of multimedia, automatic captioning and communication skills. A major difficulty for researchers in the speech recognition field is the lack of tested and reliable instruments, although current work on user response as reported by parents (Griffiths et al 2009) should result in enhanced capability in this area. With a focus on established software tools, researchers from two US universities examined the use of graphic symbols for emergent literacy (Parette et al 2008; 2009). Recent and current $\mathrm{PhD}$ studies also focus on graphic symbol use though within more developed theoretical frameworks and across the disciplines of teaching and speech and language therapy (Greenstock \& Pampoulou 2009) or the role of symbols for accessing literacy in the mainstream school (Pampoulou \& Detheridge 2007, Greenstock 2009). Specific symbol sets such as Makaton, Widgit or PCS, or symbol-enhanced teaching systems such as PECS or TEACCH, have also been the subject of research, a recent example being the study of current attitudes to Makaton within inclusive education paradigms (Sheehy \& Duffy 2009), which showed how that symbol set has moved from a role as a remedial technique to being seen as a tool for inclusion. The rapid development of symbol use within mainstream schools is also at least part of the driving force behind the development of inclusive symbol resources by multi-disciplinary teams (Mead, Mead \& Williams 2009; Mead, Mead \& Williams 2010; Mead, Mead, Sebuliba \& Williams 2010).

Braille could be seen as one of the first assistive technologies, and computers have enabled it to be a much more varied and useful tool. Audio, too, has much to offer those young learners with significantly impaired vision, and researchers at the University of Iceland have produced a review of the efficacy of audio vs. Braille for a range of everyday tasks (Shimomura, Hvannberg \& Hafsteinsson 2010). The study aimed to look at how young learners use technologies such as screen readers with audio or Braille, and to identify the barriers that may be found, as well as the strategies that support their use. The researchers also offer recommendations for interface designers and suggest future areas of research. Screen-readers have been much used by learners with impaired vision, but the various menu hierarchies that may be created on websites are interpreted variably by different 
reader software. A variety of hierarchical menu structures has been found to lead to varying results (Hochheiser \& Lazar 2010), with this study of screenreader users showing better results with broad, shallow structures than with narrow, deep ones.

Skimming and scanning remains problematic for some Web-users with impaired vision, and browsing shortcuts are mechanisms that may help in this area (Kouroupetroglou, Salampsis \& Manitsaris 2007). It has been shown (Zúnica \& Clemente 2007) through research with users with impaired vision that they see the Internet as a valuable tool for accessing information and communicating with others. However, the researchers also report that the same users found frequent and important problems of accessibility that reduced the effectiveness of these resources. Other research (Manset-Williamson, Dunn, Hinshaw \& Nelson 2008) went further and examined the role of a self-questioning strategy as a way of enhancing metacognitive strategies on the part of the learner who is struggling to use screen-readers meaningfully. Similarly, signing is a very well-developed language in use among many learners with a hearing impairment. Work continues on the effective translation of speech to avatar-based signing, and Elliott et al (2008) provide an overview of developments in this area, focusing on sign language generation from English text and the difficulties presented by grammatical and other issues.

As with the technologies for practice, there is considerable work on technologies to assist learning within Mathematics and Science curriculum areas. Young learners in the Netherlands who were identified as having learning difficulties were tested with an ICT-based assessment which was also described as a dynamic visual tool (Peltenburg et al 2009). Within the wider mainstream curriculum, and indeed within professional adult training environments, animation has long been seen as a modality offering clarity, engagement and control for the author. One mainstream school (Burdett et al 2010) has developed a wide range of animated help modules to support students with learning difficulties who have been included in the school. Future amalgamation of this work with other developments on automated captioning could be mutually beneficial. Digital video production in general has been shown to be an effective technology use for learners showing signs of challenging behaviour and those with learning difficulties (Orr 2007), although sufficient time must be allocated for the activity to be successful. 
Mobile computing has developed rapidly in recent years and a review of this field (Power and Jürgensen 2010) focussed in particular on the use of mobile technologies to assist learners with visual impairments. Covering PCs, PDAs, media players and mobile phones, the authors look at a wide variety of options now available to present textual, graphical, mathematical and Web-based documents through audio and haptic modalities. Stock et al (2008) evaluated software which aimed to increase independent access to mobile phones by people with learning difficulties, through the use of an off-the-shelf phone with special software installed, and it is increasingly the needs of users with cognitive difficulties that are considered in recent and current mobile computing use and research . Mobile phone interfaces are also the focus for a paper looking at design principles that could improve accessibility for those who struggle with literacy (Lalji \& Good 2008). Learning in the widest sense is the focus of a study of the use of a wrist-worn navigating device (Fickas, Sohlberg \& Hung 2008), in which the authors compare four different prompt modes for people with cognitive impairments. A similar result arose (Zentel et al 2007) when investigating the barriers facing Web users with cognitive difficulties; as with Fickas et al (2008), audio feedback was found to be more effective than unstructured graphical symbol support. The way forward for these users may be through designated portals which can enable users to explore the Web independently and to a greater depth (Williams \& Hanson-Baldauf 2010).

Games and puzzles have a long history of use within assistive technologies. Children on the autism spectrum have been given the opportunity to access a puzzle through innovative and interactive technologies such as multimedia tables, tangible technologies or virtual environments (Battochi et al 2008). Also working with children on the autism spectrum, Davis et al (2007) identified a deficit in narrative comprehension among these young people, and sought to address this through an interactive software system which would also recognise the social world in which they live. Reporting on this longitudinal study, the authors describe enhanced understanding of narrative components and a correlation with real-world narrative comprehension tasks. Shih, Shih and Wang (2010) also looked at technological prompts for collaboration, as they developed a driver that would allow two users with multiple disabilities to co-operate in moving a mouse. Liu, Conn, Sarkar and Stone (2008) took a different approach by investigating the ways in which technology-based tasks might elicit the affective states of liking, anxiety and engagement that they report as being important in autism intervention. The system they describe involves constant monitoring by a therapist who uses an assistive therapeutic tool, a development the authors report as being the first time that the affective states of children identified with ASD have been experimentally detected by way of physiology-based affect recognition technique. 
Users in Finland with a variety of levels of visual impairment played a series of games using audio and other support (Evreinova, Evreinov \& Raisamo 2008). Sánchez and Rodríguez (2010) developed a sound-based videogame in Chile, to be used alongside a haptic device for improving orientation and mobility in children with impaired vision. Results showed a high degree of acceptability on the part of the target user group, and researchers hope the next phase will show significant gains in the development of temporo-spatial orientation skills of children with visual impairment when navigating in unfamiliar spaces. Working with a different colleague (Sánchez \& Sáenz 2010), Sánchez has also published research on navigation for those with visual impairment through an underground railway system, with the fieldwork having taken place in the Santiago Metro. A team from Nottingham (Brown et al 2011) have used serious games alongside location-based technologies for young people with severe learning disabilities and additional sensory impairments. Locationbased services enable learning to take place in a real context, with all the support that this context and assistive technology can provide when working in tandem: for example, when route learning in a real context by young people with disabilities using an Android device.

It seems likely that robotics will have much to offer in the field of technology to assist learning, and indeed to assist daily living, although the latter is beyond the scope of this paper. The availability of gesturing technologies led to exploratory work with learners with a motor disability who were able to interact with a multimedia robotic device (Petersson \& Brooks 2007). More recently, Standen et al (2011) have evaluated the use of the Wii Nunchuk as an alternative assistive device for people with physical and intellectual disabilities who normally use switches to interact with computer software.

Assistive play was the focus for other robotics development in Canada and Portugal (Cook, Encarnação \& Adams 2010). From a rehabilitation engineering and robot design perspective, the authors aimed to define a set of desirable characteristics for robots and assistive play. Their early work has shown that, after watching the assistive play, parents and teachers thought that children were more able than they had assumed. Raya et al (2010) worked with very young children to investigate whether a head control mouse would be an effective solution for learners with motor disabilities. They found that their target group could control the cursor in this way, although they had more difficulty with finer movements. 
Assistive technologies also have learning-related uses to enable young people to participate enjoyably and meaningfully in a range of activities. This was the focus for the use of a motion-sensitive environment which provided interactive control of responsive multimedia (Brooks 2008). Not all aspects of social networking are as accessible to assistive technologies users as might be the case, as Bates, Vickers and Istance (2010) show in their discussion of the use of gaze interaction with on-line communities. Within a longitudinal study of eye-gaze technology (Bates et al 2007), and focussing in particular on Second Life, the authors show that current access possibilities do not offer effective gaze control and thus impair the ability of users to make their disability transparent. Early research into the use of Skype video communication for learning (Harrison \& Robertson 2008 ) is encouraging. Similarly, Web-based libraries open up possibilities for collaboration and cultural exchange (Komlodi 2007).

With such a range of assistive technologies available, it can be difficult for even an informed professional to be aware of the whole range of possibilities. Some see the toolkit approach as a way forward (Judge, Floyd \& Jeffs 2008); others locate the driver for assistive technology use as being the legislative framework in position, as is the case with a review of implementation in one Canadian state (Morrison 2007) which showed that the most important factor, as has often been shown, was teacher attitude and comfort with technology. Too often, ICT may be all-pervasive but not used particularly to assist or enable inclusion, as Brodin and Lindstrand (2008) found in their study of young children with motor disabilities. There is a well-developed literature on the use of assistive technologies by people with AAC needs, for example a study of children in hospitals (Sherlock 2008) which refers to previous literature on the topic and notes again the preponderance of low-tech devices. Outside of AAC, autism and to some extent sensory impairment, there is still much less research literature on technology uses to assist learning than would be expected given the very large number of contexts in which this takes place.

\section{Technology uses to enable learning}

These uses of technology make "learning possible where it was not possible before" (Abbott 2007a: 13).

Perhaps amongst the most truly enabling of technologies are those that make it possible for people to communicate where they would otherwise be unable to do so (Nianou et al 2010). Voice Output Communication Aids - VOCAs - have long been an essential component of the technologies resource bank; particular users, such as students in Further Education, will have specific needs and a case study (Howarth \& Slaughter 2009) identifies these and suggests some possible solutions. Assessing the needs of younger children is particularly 
challenging, and four case studies (Harding 2009) identify the key issues to be considered, such as the receptive language capability of the child and whether the necessary cognitive pre-requisites are in place.

Aesthetic and creative aspects of the use of technology feature less often in the literature, but can be enabling in a most profound way. The use of an immersive, multimodal user-controlled installation in France was found to have great potential (Ghedini, Faste, Carrozzino \& Bergamasco 2008). The installation, Passages, offered users the opportunity to create, explore and interact with a virtual environment in real time. Grierson (2008) also addressed creative uses of technologies, in his paper about children with multiple disabilities, including deafness and autism, making music with images. The paper describes the technical basis for the system, which involves real-time transformation of sound into moving images, and then back to sound again.

It is also unarguable that many technologies used by people with visual impairment are truly enabling, in that without those technologies it would be very difficult if not impossible for those users to access the resource in question. An Italian team describe (Dini, Ferlino, Gettani, Martinoli \& Ott 2007) how they evaluated the accessibility of educational software aimed at students with low levels of vision. They propose an educational software accessibility checklist which is intended to be used by teachers who may have little experience of children with limited vision, and covering areas such as general readability, working field extension and position, menu location and coherence, characters and colour. A team of researchers in Finland (Evreinova, Evreinov \& Raisamo 2008) looked at alternative input devices, a camera joystick and a manual version, as part of ongoing work in this area. The efficacy of the devices for user input was compared in a target acquisition task, where neither the targets nor any pointers were available visually.

Alternative interfaces were also the focus for a usability study (Fejtová, Figueiredo, Novák, Štěpánková \& Gomes 2008) which looked at hands-free interaction. For users with limited or no use of arms and hands, touchfree interfaces offer considerable promise. In this paper, two new low-cost systems are described, both making use of the user's eyes or nose movements to control the cursor. The process of using these alternatives was found to be rather slow, although this did improve over time, with the use of mouse-controlled toys being found to be helpful in building confidence and controlling home appliances. A similar focus was adopted by a group of Finnish and UK researchers (Istance, Hyrskykari, Vickers \& Chaves 2009) who investigated multiplayer online role-playing groups, such as World of Warcraft, and the potential for interacting with these through eye gaze. 
Games of a different kind were the focus in Finland, where a tactile memory game with multimodal navigation support and audio cues was developed for visually impaired children (Raisamo, Patomaki, Hasu \& Pasto 2007).

Some researchers have further developed the use of assistive technologies by children on the autism spectrum in order to enable learning where it was not previously possible. Using participatory design methodology, Cobb et al (2010) have explored two different collaborative interaction technologies: Collaborative Virtual Environments and Shared Active Surfaces. A different perspective on Collaborative Virtual Environments is provided by Cheng, Chiang and Cheng (2010) in their study of the use of these environments to develop and enhance empathy and the ability to take a particular perspective.

Also involving working within a participatory design framework, but with a focus on providing inclusive education for a boy on the autism spectrum in Germany, is a case study based in a mainstream school classroom (Lingnau \& Lenschow 2010). In this study, the researchers suggest the role of the enlightened teacher is vital, as is the emphasis on collaborative learning. Checkley et al (2010) took a different approach to participation, asking for children who use VOCAs to give their personal reactions to these technologies. The participants, three boys with autism, were clear that they found VOCA use to be pleasurable and motivating, these responses being obtained through using parents and school staff as expert guides.

Again with a focus on learners on the Autism Spectrum in Nottingham - an area of impairment more researched than some others - a study of the use of interactive whiteboards (IWBs) found potential, provided that the teacher involved was clear about the aims and objectives of the technology use (Leach 2010). Key guidelines are provided for others who wish to explore the use of IWBs with this user group. IWBs are also involved as the delivery technology for software written with the needs of users with autism in mind: Reactickles (Keay-Bright 2008). Guldberg et al (2010) focussed on the development of social skills software for children with autism within the ECHOES II learning environment. The group once again found that the benefits of participatory design were clear, as was the complex nature of social intervention. Social intervention is a major area of research within autism and technologies, and the team developing the Collaborative Puzzle Game described above have continued to explore its potential (Battocchi et al 2010). 
Researchers within Human-Computer Interaction (HCI) are well-represented within autism-related research, not surprising perhaps in view of the perceived interaction needs of this group of users. Conversation was the focus for a French project, which looked at two groups, those with autism and those developing typically, and their responses to a range of support modalities: text, speech and images (Grynszpan, Martin \& Nadel 2008). After a series of structured interventions for both groups, the researchers found that those on the autism spectrum showed poorer performance on the richer multimedia interfaces, perhaps because they lacked the ability to organise the available range of modalities. Judge \& Landeryou (2007) outline the considerable undeveloped potential for text entry, using these technologies and mobile phones, by those within the AAC community.

As has been described above, different modalities can assist in the accessibility of, for example, websites. The use of audio and image can be more than a support to those who struggle with text; such technologies can in some cases enable access by a user who is unable to cope with text. This is the focus of work by Chen et al (2009), who looked at the effect of different support modalities on the reading of digital text. Their conclusions include a call for flexible solutions, since they found that text-picture was the most suitable combination for students with autism, while those with learning difficulties were more supported by text-voice.

Robotics continues to develop its role as a discipline where there would seem to be considerable potential for current assistive technologies to be superseded or greatly enhanced. An EU project based at the University of Hertfordshire is working on the development of robot-assisted play (Robins et al 2010), with the robot playing the role of social mediator, encouraging children with special educational needs to discover a range of play styles, from solitary to collaborative play.

\section{Conclusion}

Throughout this review of the period 2007-2011, we note a continuing move from a focus on technology to a focus on use and effectiveness. This has been enabled by rapid and multiple changes and developments in the technology itself, which has become cheaper, more easily available and more widespread. It is also, often, more effective, reliable and flexible. AT and accessible products are becoming cheaper and more widely available, although the situation is complex. The increasing involvement of User Centred Design takes into account context of use and the range of stakeholders concerned; and experimental design can meet that challenge (e.g., Brown et al, 2011b). 
It is clear that there are some key areas of development within current and recent assistive technologies research. Whilst recognising the relatively small number of papers and projects involved, we put forward the following as significant issues for consideration by those in the field .

\section{User involvement}

A significant number of projects have acknowledged the need to involve users in the research which relates to them and their needs. The use of participant design approaches ensures that research projects are less likely to be abandoned at a later stage, though this needs to be at a genuine and meaningful level. A helpful measure here would be the levels of participation identified by Hart (1992) with his Ladder of Young People's Participation, ranging from tokenism and decoration (classified by Hart as non-participation) through information to shared decision-making.

\section{Mobile mainstream devices}

The rapid deployment and popular acceptance of mobile phones, particularly smartphone and other personal digital assistants, has led to an understandable demand for digital assistive technologies to be mediated through these devices. Products such as the Apple iPhone 4 and Windows 7 have options for accessibility built in rather than there being a need to add it as an afterthought.

\section{Visibility of assistive technology use}

Assistive technologies have become much more visible, particularly as a result of the move of speech synthesis, speech recognition and graphic symbols into mainstream and inclusive settings.

\section{Interaction and collaboration}

Much of the research included in this paper focuses on interaction between people with disabilities and, importantly, with those not identified as having disabilities. Interactional routes are multiplying and diversifying, as has been identified in the wider literature on multimodalities and changing literacies. 
One of the few trends driven by technological advances rather than changing attitudes is the rapid development in alternative interfaces such as brain control, gesture control and eye-gaze. The use of robotics is another developing technological trend. The move towards a greater focus on Natural User Interfaces which accompanies these emerging technologies is sympathetic to people with disabilities. It will be important that developing interfaces reflect young people's experiences and expectations, for example of games controllers, as well as the full range of complex and multiple disabilities.

\section{Inclusive Design}

Increasingly, researchers are choosing to focus on those devices (e.g., Smart phones) and Software Tools (e.g., games engines such as Unreal Development Kit) that a wide range of users would choose to use themselves, and extend their application to also take into account the learning and interaction needs of people with disabilities.

As can be seen from this series of emerging themes, almost all can be characterised as being part of the imperative to move from the special to the mainstream, from the medical to the social model and from adaptation to meeting the needs of all. Assistive technologies research is becoming ever more inclusive. In order to assess impact, however, we need longer term studies and for these to be led by teams who are independent from the developers of the technologies in question. Not only users and carers but also gatekeepers need to be involved in such research. No matter how inclusively and expertly designed the technology, if the gatekeepers (teachers, teaching assistants and therapists for example) are not trained in its use or sympathetic to it, the beneficiaries will never get the chance to use it. There are issues of classification to be dealt with here, and awareness and knowledge of products can be difficult to maintain in a rapidly changing field. However, European thematic networks such as ETNA and ATIS4All are providing online resources to address these issues.

Despite these moves, there is growing awareness of that version of the digital divide that affects those who may still not be fully included in society, due to learning difference or disability as well as socio-economic factors (McKenzie 2007). Noting that technology could form a mechanism for providing social capital, McKenzie goes on to state the continuing deficiencies in current society. 
...people with learning disabilities generally still experience significant barriers to genuine social participation. .... [and] can be considered to be digitally excluded... IT can help [and can re-link the marginalised to their community]. However, there is still a distance to go before this goal can be achieved.

(McKenzie 2007: 21)

Charities such as the Children's Society (Murray 2007) and MENCAP have been clear in their call for all children to access technology and online resources: the use of appropriate assistive and enabling technologies is one way in which this can begin to be achieved. It would seem likely that a key focus for assistive technologies researchers for the next few years should be continued consideration of the affordances of these technologies for bridging the digital divide, enhancing inclusion, and minimising the "differentness" of assistive technologies. In the most recent papers covered, we welcome a renewed emphasis on access to assistive technology as a human right.

Assistive technologies are included among the [UN Convention on the Rights of Persons with Disabilities] measures to ensure three specific human rights. First, the right to freedom of expression and opinion and access to information should be ensured...

Second, to ensure the right to education, governments should facilitate learning of Braille and augmentative and alternative communication. They should also ensure that education is delivered using the most appropriate modes and means of communication.

Third, governments are required to facilitate the use of assistive technologies to ensure the right to participate in political and public life...

(Borg et al, 2011)

\section{Declaration of interest}

The authors report no conflict of interest. The literature review on which this paper is based was one of the outcomes of the ESRC-funded Seminar Series: Researching Assistive Technologies (King's College London/De Montfort University Leicester).

\section{References}

Abbott, C. (2007a). Defining assistive technologies - a discussion Journal of Assistive Technologies, 1(1), 6-9.

Abbott, C. (2007b). E-inclusion: Learning Difficulties and Digital Technologies. Bristol: Futurelab. 
Abbott, C. (2010). Perceptions, experiences and desired changes: responses from the conference floor Journal of Assistive Technologies, 4(4), 36-39.

Abbott, C., Brown, D., Evett, L., Standen, P. \& Wright, J. (2011) Learning difference and digital technologies: a literature review of research involving children and young people using assistive technologies 2007-2010. Accessed on $4^{\text {th }}$ Jan 2012.

www.kcl.ac.uk/sspp/departments/education/research/crestem/steg/recentproj/assistivetech.aspx. Bailey, P. (2009). The Multi-Modal nature of communication between natural speakers and aided speakers Communication Matters, 23(3), 33-36.

Bailey, P., \& Bunning, K. (2010). 'Telling Stories' A pilot study investigating the key features of AAC speakers' fictional narrative interaction. Communication Matters, 24(3), 29-32.

Bates, R., Donegan, M., Istance, H. O., Hansen, J. P., Räihä, K.-J. (2007). Introducing COGAIN: communication by gaze interaction. Univers. Access Inf. Soc., 6(2), 159-166.

Bates, R., Vickers, S., \& Instance, H. O. (2010). Gaze interaction with virtual on-line communities: levelling the playing field for disabled users. Universal Access in the Information Society, 9(3), 261-272.

Battocchi, A., Ben-Sasson, A., Esposito, G., Gal, E., Pianesi, F., Tomasini, D., et al. (2010). Collaborative puzzle game: a tabletop interface for fostering collaborative skills in children with autism spectrum disorders. Journal of Assistive Technologies, 4(1), 4-13.

Battocchi, A., Gal, E., Sasson, A. B., Pianesi, F., Venuti, P., Zancanaro, M., et al. (2008). Collaborative puzzle game - an interface for studying collaboration and social interaction for children who are typically developed or who have Autism Spectrum Disorder. Paper presented at the 7th ICDVRAT with ArtAbilitation.

Borg, J., Larsson, S. \& Östergren, P. (2011). The right to assistive technology: for whom, for what and by whom? Disability \& Society. 26 (2). 151-167.

Brodin, J., \& Lindstrand, P. (2008). ICT and inclusive education in primary schools - pupils with motor disabilities. Journal of Assistive Technologies, 2(3), 16-23.

Brooks, A. L. (2008). Towards a platform of alternative and adaptive interactive systems for idiosyncratic special needs. Paper presented at the 7th ICDVRAT with ArtAbilitation.

Brown D. J., McIver E, Standen P. J. and Dixon, P. (2008). Can Serious Games Improve Memory Skills in People with ID? Journal of Intellectual Disability Research. 52 (8, 9), 678. 
Brown, D., Standen, P., Evett, L., Battersby, S., (2010) Designing serious games for people with dual diagnosis: learning disabilities and sensory impairments in Zemliansky, P. and Wilcox, D. M., (Eds.) Design and Implementation of Educational Games: Theoretical and Practical Perspectives. New York: IGI Global Brown, D. J., McHugh, D., Standen, P., Evett, L., Shopland, N., \& Battersby, S. (2011). Designing locationbased learning experiences for people with intellectual disabilities and additional sensory impairments. Computers \& Education, 56(1), 11-20.

Brown, D. J. \& Standen, P. (2011 under review) Can participating in games based learning improve mathematics skills in students with intellectual disabilities. Submitted to SeGAH www.ica.pt/segah2011 Burdett, R., Hulbert, V., Robinson, M., Richardson, M., Shaw, H., \& Will, S. (2010). Making learning easier for SEN students through the use of film and animation. Journal of Assistive Technologies, 4(2), 40-43

Burke, R. V., Andersen, M. N., Bowen, S. L., Howard, M. R., \& Allen, K. D. (2010). Evaluation of two instruction methods to increase employment options for young adults with autism spectrum disorders. Research in Developmental Disabilities, 31(6), 1223-1233.

Checkley, R., Hodge, N., Chantler, S., Reidy, L., \& Holmes, K. (2010). What children on the autism spectrum have to 'say' about using high-tech voice output communication aids (VOCAs) in an educational setting. Journal of Assistive Technologies, 4(1), 25-37.

Chen, M.-C., Wu, T.-F., Lin, Y.-L., Tasi, Y.-H., \& Chen, H.-C. (2009). The effect of different representations on reading digital text for students with cognitive disabilities. British Journal of Educational Technology, 40(4), 764-770.

Cheng, Y., Chiang, H.-C., Ye, J., \& Cheng, L.-h. (2010). Enhancing empathy instruction using a collaborative virtual learning environment for children with autistic spectrum conditions. Computers \& Education, 55(4), 1449-1458.

Cobb, S. V., Millen, L., Glover, T., Parsons, S., Garib-Penna, S., Weiss, P. L., et al. (2010). Integrative approach for designing collaborative technologies for social competence training in children with autism spectrum conditions. Paper presented at the 8th International Conference on Disability, Virtual Reality and Associated Technologies.

Cook, A., Encarnacao, P., \& Adams, K. (2010). Robots: Assistive technologies for play, learning and cognitive development. Technology and Disability, 22, 127-145. 
Davis, M., Dautenhahn, K., Nehaniv, C. L., \& Powell, S. D. (2007). The narrative construction of our (social) world: steps towards an interactive learning environment for children with autism. Universal Access in the Information Society, 6(2), 145-157.

Davis, M., Dautenhahn, K., Powell, S. D., \& Nehaniv, C. L. (2010). Guidelines for researchers and practitioners designing software and software trials for children with autism. Journal of Assistive Technologies, 4(1), 38-48.

Dini, S., Ferlino, L., Gettani, A., Martinoli, C., \& Ott, M. (2007). Educational software and low vision students: evaluating accessibility factors. Universal Access in the Information Society, 6(1), 15-29.

Elliott, R., Glauert, J. R. W., Kennaway, J. R., Marshall, I., \& Safar, E. (2008). Linguistic modelling and language-processing technologies for Avatar-based sign language presentation. Universal Access in the Information Society, 6(4), 375-391.

Evett L. \& Brown D., (2005) Text formats and web design for visually impaired and dyslexic readers - Clear Text for All, Interacting with Computers, 17, 453-472

Evett, L., Battersby, S., Ridley, A., \& Brown D. J. (2009). An interface to virtual environments for people who are blind using Wii technology - mental models and navigation. Journal of Assistive Technologies, Vol 3, issue 2, pp.30-39.

Evreinova, T., Evreinov, G., \& Raisamo, R. (2008). A camera-joystick for sound-augmented non-visual navigation and target acquisition: a case study. Universal Access in the Information Society, 7(3), 129-144. Evreinova, T. V., Everinov, G., \& Raisamo, R. (2008). Non-visual game design and training in gameplay skill acquisition - A puzzle game case study. Interacting with Computers, 20, 386-405.

ETNA (includes link to ATIS4all) www.etna-project.eu

Fejtová, M., Figueiredo, L., Novák, P., Stepankova, O., \& Gomes, A. (2008). Hands-free interaction with a computer and other technologies. Universal Access in the Information Society, 8(4), 277-295.

Fickas, S., Sohlberg, M., \& Hung, P.-F. (2008). Route-following assistance for travelers with cognitive impairments: A comparison of four prompt modes. International Journal of Human-Computer Studies, 66(12), 876-888.

Fix the Web (2011) www.fixtheweb.net/about Forrester Research, Inc. (2004). Accessible technology in computing: examining awareness, use, and future potential, Cambridge, MA: 22-41.

GALlOWAY, J. 2009. Harnessing Technology for Every Child Matters and Personalised Learning, London, Routledge. 
Ghedini, F., Faste, H., Carrozzino, M., \& Bergamasco, M. (2008). Passages - a 3D artistic interface for child rehabilitation and special needs. Paper presented at the 7th ICDVRAT with ArtAbilitation, Maia, Portugal. Greenstock, L., \& Pampoulou, E. (2009). Exploring the use of graphic symbols. Communication Matters, 24(2), $32-35$.

Greenstock, L. (2009) 'Using graphic symbols': an investigation into the experiences and attitudes of a range of practitioners using graphic symbols with children in the Foundation Stage (three to five year olds) school settings, De Montfort University [Unpublished PhD Thesis]

Gregor, P., \& Dickinson, A. (2007). Cognitive difficulties and access to information systems: an interaction design perspective. Universal Access in the Information Society, 5(4), 393-400.

Grierson, M. (2008). Making music with images: interactive audioviosual performance systems for the deaf. Paper presented at the 7th ICDVRAT with ArtAbilitation.

Griffiths, T. (2009). Exploring multiple factors affecting participation outcomes for children with communication aids. Communication Matters, 24(2), 29-31.

Groenewegen, S., Heinz, S., Fröhlich, B., \& Huckauf, A. (2008). Virtual world interfaces for special needs education based on props on a board. Computers \& Graphics, 32(5), 589-596.

Grynszpan, O., Martin, J.-C., \& Nadel, J. (2008). Multimedia interfaces for users with high functioning autism: An empirical investigation International Journal of Human-Computer Studies, 66(8), Pages 628-639.

Guldberg, K., Porayska-Pomsta, K., Good, J., \& Keay-Bright, W. (2010). ECHOES II: the creation of a technology enhanced learning environment for typically developing children and children on the autism spectrum. Journal of Assistive Technologies 4(1), 49-53.

Harding, C. (2009). Using switches with pre-school children. Communication Matters, 23(3), 11-15.

Harrison, M., \& Robertson, Z. (2009). Skype network for communication aid users. Communication Matters, 23(2), 9-12.

Hart, R. (1992). Children's Participation from Tokenism to Citizenship. Florence: UNICEF Innocenti Research Centre.

Hen, L., Josman, N., \& Rosenblum, S. (2010). Tele-evaluation and intervention among adolescents with handwriting difficulties - Computerised Penmanship Evaluation Tool (ComPET) implementation. Paper presented at the 7th ICDVRAT with ArtAbilitation.

Hochheiser, H., \& Lazar, J. (2010). Revisiting breadth vs. depth in menu structures for blind users of screen readers. Interacting with Computers, 22(5), 389-398. 
Horton, S. (2006).Access by Design: A Guide to Universal Usability for Web Designers. Berkeley, CA: New Riders.

Howarth, L., \& Slaughter, R. (2009). Can we provide the bells and whistles? Communication Matters, 23(3), 24-28.

Instance, H., Hyrskykari, A., Vickers, S., \& Chaves, T. (2009). For Your Eyes Only: Controlling 3D online games by eyegaze. Paper presented at the INTERACT 2009.

ISO 9999. (2007) www.iso.org accessed on 06/06/11

Jonge, D. d., Scherer, M. J., \& Rodger, S. (2007). Assistive Technology in the Workplace. St Louis: Mosby Elsevier.

Judge, S., Floyd, K., \& Jeffs, T. (2008). Using an Assistive technology Toolkit to promote inclusion. Early Childhood Education Journal, 36, 121-126.

Judge, S., \& Landeryou, M. (2007). Disambiguation (Predictive Texting) for AAC. Communication Matters, 22(2), 37-41.

Keay-Bright, W. (2008). ReacTickles Global: Can mobile technologies encourage playful social interaction? Journal of Assistive Technologies, 2(3), 42-45.

Komlodi, A. (2007). Evaluating a cross-cultural children's online book community: lessons learned for sociability, usability and cultural exchange. Interacting with Computers, 19, 494-511.

Konur, O. (2010). Computer-assisted teaching and assessment of disabled students in higher education: the interface between academic standards and disability rights. Journal of Computer Assisted Learning, 23(3), $207-$ 219.

Kouroupetroglou, C., Salampasis, M., \& Manitsaris, A. (2007). Browsing shortcuts as a means to improve information seeking of blind people in the WWW. Universal Access in the Information Society, 6(3), 273-283. Lalji, Z., \& Good, J. (2008). Designing new technology for illiterate populations: A study in mobile phone interface design. Interacting with Computers, 20, 574-586.

Lancioni, G. E., O'Reilly, M. F., Singh, N. N., Sigafoos, J., Oliva, D., \& Severini, L. (2008). Three persons with multiple disabilities accessing environmental stimuli and asking for social contact through microswitch and VOCA technology. Journal of Intellectual Disability Research, 52(4), 327-336.

Langdon, P., \& Thimbleby, H. (2010). Inclusion and interaction: Designing interaction for inclusive populations. Interacting with Computers, 22, 439-448. 
Leach, C. (2010). The use of Smartboards and bespoke software to develop and deliver an inclusive, individual and interactive learning curriculum for students with ASD Journal of Assistive Technologies, 4(1), 54-57. Lin, Y.-L., Chen, M.-C., Wu, T.-F., \& Yeh, Y.-M. (2008). The effectiveness of a pedagogical agent-based learning system for teaching word recognition to children with moderate mental retardation. British Journal of Educational Technology, 39(4), 715-720.

Lingnau, A., \& Lenschow, H. (2010). Scenarios for computer-supported learning in a special needs classroom. Journal of Assistive Technologies, 4(2), 26-35.

Liu, C., Conn, K., Sarkar, N., \& Stone, W. (2008). Physiology-based affect recognition for computer-assisted intervention of children with Autism Spectrum Disorder. International Journal of Human-Computer Studies, 66(9), 662-677.

Liu, C.-C., \& Hong, Y.-C. (2007). Providing hearing-impaired students with learning care after classes through smart phones and the GPRS network. British Journal of Educational Technology, 38(4), 727-741.

Majaranta, P., \& Bates, R. (2009). Special issue: Communication by gaze interaction. Universal Access in the Information Society, 8(4), 239-240.

Manset-Williamson, G., Dunn, M., Hinshaw, R., \& Nelson, J. M. (2008). The Impact of Self-Questioning Strategy Use on the Text-Reader Assisted Comprehension of Students with Reading Disabilities. International Journal of Special education, 23(1), 123-135.

McGuiness, A., \& Farrand, L. (2010). AAC and Autism. How are people reallu using voice output communication aids? Communication Matters, 24(3), 35-37.

McKenzie. (2007). Digital divide: the implications for social inclusion. Learning Disability Practice, 10(6), 1621.

McMorran, R. (2009). Head switches to eye gaze Communication Matters, 24(1), 9-15.

Mead, L., Mead, L., Sebuliba, P., \& Williams, L. (2010). Community cohesion: creating and using interactive whiteboard games. Journal of Assistive Technologies, 4(4), 40-44.

Mead, L., Mead, L., \& Williams, L. (2009). Cross-agency collaboration using visual learning techniques to support inclusion through a healthy eating project. journal of assistive technologies, 3(1), 32-36.

Mead, L., Mead, L., \& Williams, L. (2010). 'Keeping Safe' - a community cohesion project linking health with education. Journal of Assistive Technologies, 4(2), 36-39.

Microsoft Corporation. (2009). Engineering Software for Accessibility, Redmond, Washington: Microsoft Press. 
Molen, M. J. v. d., Luit, J. E. H. V., Molen, M. W. v. d., Klugkist, I., \& Jongmans, M. J. (2010). Effectiveness of a computerised working memory training in adolescents with mild to borderline intellectual disabilities. Journal of Intellectual Disability Research, 54(5), 433-447.

Moll, J., Huang, Y., \& Sallnäs, E.-L. (2010). Audio makes a difference in haptic collaborative virtual environments. Interacting with Computers, 22(6), 544-555.

Morrison, K. (2007). Implementation of Assistive Computer Technology: A Model for School Systems. International Journal of Special education, 22(1), 83-95.

Murray, M. (2007). Every child has a right to accessible information via the web. Journal of Assistive Technologies, 1(2), 35-38.

Nianou, D. (2009). The experience of providing rehabilitation for patients with locked-in syndrome through the use of communication aids: A qualitative study Communication Matters, 23(1), 7-11.

Orr, P. P. (2007). Digital Video Intervention with Special Populations: Looking for Inherent Qualities. International Journal of Special Education, 22(1), 118-124.

Pampoulou, E., \& Detheridge, C. (2007). The role of symbols in the mainstream to access literacy. Journal of Assistive Technologies, 1(1), 15-21.

Parette, H., Boeckmann, N., \& Hourcade, J. (2008). Use of Writing with Symbols 2000 software to facilitate emergent literacy development. Early Childhood Education journal, 36, 161-170.

Parette, H., Hourcade, J., Dinelli, J., \& Boeckmann, N. (2009). Using Clicker 5 to enhance emergent literacy in young learners. Early Childhood Education Journal, 36, 355-363.

Peltenburg, M., Van Den Heuvel-Panhuizen, M., \& Doig, B. (2009). Mathematical power of special-needs pupils: An ICT-based dynamic assessment format to reveal weak pupils' learning potential1. British Journal of Educational Technology, 40(2), 273-284.

Petersson, E., \& Brooks, A. (2007). Non-formal therapy and learning potentials through human gesture synchronised to robotic gesture. Universal Access in the Information Society, 6, 167-177.

PopCap Games. (2008). Survey:'Disabled Gamers' Comprise 20\% of Casual Video Games Audience',PopCap studios. popcap.mediaroom.com/index.php?s=43\&item=30. Retrieved 30/9/10.

Power, C., \& Jürgensen, H. (2010). Accessible presentation of information for people with visual disabilities. Universal Access in the Information Society, 9(2), 97-119.

Puttnam, D. (2009). "I hope we'll achieve the political legitimacy of the games industry." $7^{\text {th }}$ July 2009. www.guardian.org.uk accessed on $6^{\text {th }}$ June 2011. 
Raisamo, R., Patomäki, S., Hasu, M., \& Pasto, V. (2007). Design and evaluation of a tactile memory game for visually impaired children. Interacting with Computers, 19(2), 196-205.

Raya, R., Roa, J. O., Rocon, E., Ceres, R., \& Pons, J. L. (2010). Wearable inertial mouse for children with physical and cognitive impairments. Sensors and Actuators A: Physical, 162(2), 248-259.

Raymaekers, C. (2009). Editorial: Special issue on enactive interfaces. Interacting with Computers, 21(1-2), 1-2.

Read, J. C. (2007). A study of handwriting recognition for text entry by children. Interacting with Computers, 19(1), 57-69.

RECALL recall-project.eu

Robins, B., Ferrari, E., Dautenhahn, K., Kronreif, G., Prazak-Aram, B., Gelderblom, G.-J., et al. (2010).

Human-centred design methods: Developing scenarios for robot assisted play informed by user panels and field trials International Journal of Human-Computer Studies, 68(12), Pages 873-898.

Rose, D. H., \& Strangman, N. (2007). Universal Design for Learning: meeting the challenge of individual learning differences through a neurocognitive perspective. Universal Access in the Information Society, 4, 381391.

Salminen, A.-L. (2008). European research related to assistive technology for disabled children. Technology and Disability, 20, 173-178.

Sanchez, J. (2010). Videogame for improving orientation and mobility in blind children. Paper presented at the 8th International Conference on Disability, Virtual Reality and Associated Technologies.

Sánchez, J., \& Sáenz, M. (2010). Metro navigation for the blind. Computers \& Education, 55(3), 970-981.

Savidis, A., Grammenos, D., \& Stephanidis, C. (2007). Developing inclusive e-learning and e-entertainment to effectively accommodate learning difficulties. Universal Access in the Information Society, 4.

Saz, O., Yin, S.-C., Lleida, E., Rose, R., Vaquero, C., \& Rodríguez, W. R. (2009). Tools and Technologies for Computer-Aided Speech and Language Therapy. Speech Communication, 51(10), 948-967.

Seo, Y.-J., \& Bryant, D. P. (2009). Analysis of studies of the effects of computer-assisted instruction on the mathematics performance of students with learning disabilities. Computers \& Education, 53(3), 913-928. Seo, Y.-J., \& Woo, H. (2010). The identification, implementation, and evaluation of critical user interface design features of computer-assisted instruction programs in mathematics for students with learning disabilities. Computers \& Education, 55(1), 363-377.

Sheehy, K., \& Duffy, H. (2009). Attitudes to Makaton in the ages of integration and inclusion. International Journal of Special Education, 24(2), 91-102. 
Sherlock, C. (2008). A survey of AAC need in a children's hospital. Communication Matters, 22(1), 5-8.

Shih, C.-H., Shih, C.-T., \& Wang, S.-K. (2010). Assisting people with disabilities improves their collaborative pointing efficiency with a Multiple Cursor Dynamic Pointing Assistive Program. Research in Developmental Disabilities, 31(6), 1251-1257.

Shimomura, Y., Hvannberg, E. T., \& Hafsteinsson, H. (2010). Accessibility of audio and tactile interfaces for young blind people performing everyday tasks. Universal Access in the Information Society, 9(4), 297-310.

Sik Lányi C., Brown, D.J., Standen, P., Lewis, J., Butkute, V. (2010) User interface evaluation of serious games for students with intellectual disability, Lecture Notes in Computer Science, LNCS 6179, ICCHP 2010, Part 1, Springer Verlag Berlin-Heidelberg, 227-334

Spannagel, C., Girwidz, R., Löthe, H., Zendler, A., \& Schroeder, U. (2008). Animated demonstrations and training wheels interfaces in a complex learning environment. Interacting with computers, 20(1), 97-111. Standen, P. J., Camm, C., Battersby, S., Brown, D. J., \& Harrison, M. (2011). An evaluation of the Wii Nunchuk as an alternative assistive device for people with intellectual and physical disabilities using switch controlled software. Computers \& Education, 56(1), 2-10.

Starcic, A. I., \& Niskala, M. (2010). Vocational students with severe learning difficulties learning on the Internet. British Journal of Educational Technology, 41(6), E155-E159.

Steinkuehler, C. (2008). Massively multiplayer online games as an educational technology: An outline for research. Educational Technology, 48(1), (10-21).

Stock, S. E., Davies, D. K., Wehmeyer, M. L., \& Palmer, S. B. (2008). Evaluation of cognitively accessible software to increase independent access to cellphone technology for people with intellectual disability. Journal of Intellectual Disability Research, 52(12), 1155-1164.

Townend, G., \& Judge, S. (2009). What do users really want from Communication Aids? Communication Matters, 24(2), 36-39.

Umanski, D., Kogovsek, D., Ozbic, M., \& Schiller, N. (2010). Development of a voice-based rhythm game for training speech motor skills of children with speech motor disorders. Paper presented at the 8th International Conference on Disability, Virtual Reality and Associated Technologies.

Visell, Y. (2009). Tactile sensory substitution: Models for enaction in HCI. Interacting with Computers, 21(3853).

W3C (2008a) Web Accessibility Quick Tips: WCAG 2 at a glance. www.w3.org/WAI/WCAG20/glance/ accessed 27/2/09 
W3C (2008b) How to Meet WCAG 2.0: A customizable quick reference to Web Content Accessibility

Guidelines 2.0 requirements (success criteria) and techniques. www.w3.org/WAI/WCAG20/quickref/ accessed $27 / 2 / 09$

W3C (2008c) Web Content Accessibility Guidelines (WCAG) 2.0. www.w3.org/TR/WCAG/ accessed 27/2/09

Wald, M., \& Bain, K. (2008). Universal access to communication and learning: the role of automatic speech recognition. Universal Access in the Information Society, 6(4), 435-477.

Williams, C. (2008). Unintentional intrusive participation in multimedia interactive environments. Paper presented at the 7th ICDVRAT with ArtAbilitation.

Williams, P., \& Hanson-Baldauf, D. (2010). Testing a web information portal for people with learning disabilities. Journal of Research in Special Educational Needs, 10(1), 42-51.

Yang, H. J., Lay, Y. L., Liou, Y. C., Tsao, W. Y., \& Lin, C. K. (2007). Development and evaluation of music=learning system for the hearing impaired. Journal of Computer Assisted Learning, 23(6), 466-476. Zentel, P., \& Opfermann, M. (2007). Multimedia learning and the Internet: ensuring accessibility for people with learning disabilities. Journal of Assistive Technologies, 1(1), 22-32.

Zúnica, R. R., \& Clemente, V. Á. (2007). Research on Internet use by Spanish-speaking users with blindness and partial sight. Universal Access in the Information Society, 6(1), 159-166. 